\title{
A EBC e a Comunicação Pública no Brasil
}

\author{
EBC and Public Communication in Brazil
}

\author{
Akemi Nitahara* \\ Cristina Rego Monteiro da Luz ${ }^{* *}$
}

\section{RESUMO}

Este trabalho traz resultados da pesquisa sobre o caminho de institucionalização da comunicação pública, feita no mestrado do Programa de Pós-Graduação em Mídias Criativas na Escola de Comunicação da UFRJ, com os principais marcos legais e históricos dos veículos da Empresa Brasil de Comunicação (EBC). O levantamento traz as regulamentações desde o início da radiodifusão no país até a Lei $n^{0}$ 13.417/2017, que alterou a EBC após o impeachment presidencial de 2016. O levantamento analisa a compreensão conceitual e gestão governamental na comunicação pública do Brasil até os 12 primeiros anos da EBC, em projetos como a teleducação e a propaganda de atos do governo.

Palavras-chave: EBC; TV Brasil; Rádio Nacional; Rádio MEC; Agência Brasil.

\begin{abstract}
This work shows the results of a research about public communication institutional path to obtain the Master's degree at the UFRJ, on the legal and historical milestones of the vehicles of the Empresa Brasil de Comunicação (EBC). The survey brings the regulamentations from the beginning of broadcasting in Brazil up to Law No. 13.417/2017, which modified the status of EBC after the 2016 presidential impeachment. The survey analyzes the conceptual understanding and government management in public communication in Brazil up to the first 12 years of the EBC, with projects such as tele-education and propaganda of government acts.
\end{abstract}

Keywords: EBC; TV Brasil; Rádio Nacional; Rádio MEC; Agência Brasil.

\section{INTRODUÇÃO}

Este artigo tem base na dissertação "As Origens da EBC - Mapa Interativo Histórico da Empresa Brasil de Comunicação: 1923 a 2019", que resultou em um site interativo realizado para a obtenção do mestrado profissional em Mídias Criativas da Escola de Comunicação da Universidade Federal do Rio de Janeiro em dezembro de 2019. A partir do registro digital do histórico das origens da EBC, pretende-se delinear aspectos indicativos da implementação da comunicação pública no Brasil.

\footnotetext{
* Mestre em Criação e Produção de Conteúdos Digitais pelo Programa de Pós-Graduação em Mídias Criativas da Escola de Comunicação da Universidade Federal do Rio de Janeiro (PPGMC-ECO/UFRJ). Jornalista da Empresa Brasil de Comunicação (EBC). Endereço: Rua da Relação 18 - Lapa, Rio de JaneiroRJ. CEP: 20.231-110. Telefone: (21) 2117-6453. E-mail: akemi.nitahara@gmail.com.

** Doutora em Comunicação e Cultura pelo Programa de Pós-Graduação em Comunicação da Universidade Federal do Rio de Janeiro (ECO/UFRJ). Professora Associada do Departamento de Expressão e Linguagens da ECO/UFRJ. Av. Pasteur, 250 - Urca, Rio de Janeiro-RJ. CEP: 22.290-240. Telefone: (21) 3938-5073. E-mail: crmluz@globo.com.
} 
A EBC é responsável pelos veículos públicos TV Brasil, Rádio Nacional (AM do Rio de Janeiro, AM e FM de Brasília, Ondas Curtas da Amazônia e AM e FM do Alto Solimões), Rádio MEC (AM e FM do Rio de Janeiro e AM de Brasília), e pelas agências de notícias Agência Brasil e Radioagência Nacional, além do Portal EBC. Também responde pelos serviços governamentais TV NBR, pelo programa A Voz do Brasil e pela Rede Nacional de Rádios, além da distribuição de publicidade legal e do monitoramento e análise de mídias, segmentos que serão abordados apenas quando tiverem interseção com os serviços considerados como de comunicação pública, foco principal do trabalho.

A pesquisa foi norteada pelos Indicadores de qualidade nas emissoras públicas, instituídos pela representação da Unesco no Brasil (BUCCI, CHIARETTI e FIORINI, 2012). Estes indicadores definem os objetivos da comunicação pública, tais como a oferta de elementos que atendam às circunstâncias sociais específicas, propiciando "gestão transparente e uma programação cuja qualidade possa ser mensurável segundo os padrões valorizados pela comunidade a que ela se destina" (BUCCl et al, 2012, p.12).

Foi utilizado também como referência o modelo da BBC de Londres, descrito por Mendel (2011) no livro Serviço público de radiodifusão como parâmetro mundial em qualidade na comunicação pública.

Os propósitos públicos devem apoiar a cidadania e a sociedade civil, promover a educação e o aprendizado, estimular a criatividade e a excelência cultural, representar o Reino Unido e levá-lo ao mundo e o mundo até ele (MENDEL, 2011, p.83).

Há características, no entanto, que distinguem os projetos de comunicação pública por distintas necessidades e objetivos. A comunicação pública nasce nas democracias tardias, como o Brasil, como um contraponto à comunicação governamental e à mídia comercial, para complementar seus conteúdos e discursos (BUCCl et al, 2012, p.9). Como apontado por Valente (2009, p.13), a EBC foi criada na condição de "complementaridade marginal" aos conteúdos ofertados pela comunicação comercial.

Considerando a disputa de poder envolvida no meio midiático, o trabalho utiliza a economia política da comunicação (EPC) de Vincent Mosco (2009) para analisar o sistema público, levando em conta relações sociais e contradições do capitalismo em cada época histórica abordada na pesquisa.

\footnotetext{
Além disso, essa perspectiva significa que a realidade é estabelecida ou constituída por muitas fontes e não pode ser reduzida ao essencialismo da economia (por exemplo, apenas o dinheiro guia a mídia) ou da cultura (por exemplo, os valores das pessoas guiam a mídia). A abordagem também traz à tona os conceitos de mudança social, processos sociais e relações sociais, mesmo que isso signifique reavaliar a ênfase que a economia política tradicionalmente coloca em instituições sociais, como empresas de mídia, ou em ver a classe social como uma categoria e não, como sugere essa abordagem, como um relacionamento social (MOSCO, 2009, p.1, tradução nossa).
}

A cartografia nas ciências sociais descrita por Martín-Barbero (2002) foi a base para o mapeamento histórico, utilizando aqui o sentido figurado de mapa. Segundo ele, o método serve para construir imagens das relações e dos labirintos, não apenas delimitar fronteiras, como uma representação simplificada do real. Permite uma 
estratégia útil para organizar, disponibilizar e analisar informações, além de mediar as relações comunicativas.

Barbero (2002, pp. 17 e 18) juntou aos conceitos tradicionais de mediação, aspectos de socialidade, institucionalidade, tecnicidade e ritualidade no mapeamento das mediações comunicativas, levando um olhar antropológico para a identificação de novas relações sociais, culturais e políticas. A inclusão destes elementos enriquece as possibilidades de análise da história da comunicação pública na realidade brasileira, imbricada em seu contexto histórico elitista, de pouca participação política mas de grande riqueza cultural.

\title{
PRIMÓRDIOS HISTÓRICOS
}

A EBC foi criada em outubro de 2007, mas a história dos veículos administrados por ela começa com a história da radiodifusão no país. No dia 20 de abril de 1923, Edgard Roquette-Pinto e Henrique Morize colocam no ar a primeira emissora do Brasil, a Rádio Sociedade do Rio de Janeiro, patrocinada pela Academia Brasileira de Ciências, que 13 anos mais tarde viria a ser a Rádio MEC.

A inspiração era elitista (AZEVEDO et al., 2009, p.42). De acordo com Pieranti (2018, p.120), "Roquette-Pinto defendia que o novo meio seria fundamental para 'educar' a população, tendo em vista a alta taxa de analfabetismo no país". Aqui vemos o conceito de estruturação da EPC de $\operatorname{Mosco}(2009$, p.2), em que a relação social é criada com base na classe social. De um lado o cientista intelectual e de outro a massa trabalhadora analfabeta que precisa ser educada. Sintomaticamente, até hoje a Rádio MEC FM é o último refúgio para os ouvintes da música clássica no dial brasileiro.

Laurindo Leal Filho (in CARMONA, 2003, p.79) destaca que os objetivos defendidos por Roquette-Pinto eram os mesmos da BBC britânica, fundada na mesma época pelo engenheiro escocês John Reith.

\begin{abstract}
Roquette-Pinto dizia que todos os lares espalhados pelo imenso território brasileiro receberiam conforto moral da ciência e da arte pelo rádio; na Inglaterra, John Reith afirmava que o objetivo do rádio era o de levar para dentro do maior número possível de lares tudo o que de melhor existia em cada parte do esforço e da realização humana (LEAL FILHO in CARMONA, 2003, p.79).
\end{abstract}

A história da Rádio Nacional começa em 1933, quando foi constituída a Sociedade Civil Brasileira Rádio Nacional. A emissora foi inaugurada pelo jornal A Noite em 12 de setembro de 1936, em ondas médias, com a música "Luar do Sertão" (de João Pernambuco e Catulo da Paixão Cearense).

Também em 1936, Roquette-Pinto doa a Rádio Sociedade ao Ministério da Educação e Saúde Pública, e a emissora vira Rádio MEC. Segundo Azevedo et al. (2009, p.270), ele condicionou a transferência "à manutenção de seu caráter educativo" e à vinculação administrativa ao ministério. Mas a contextualização política tem sempre muita influência na estrutura das empresas de comunicação.

A década de 1930 foi marcada pelo início da organização dos serviços de comunicação e inteligência do governo federal, com a criação, por Getúlio Vargas, do Departamento Oficial de Propaganda (DOP) em 1931. Entre as suas atribuições estava a "elaboração de um Boletim Diário de Informações Oficiais destinado à Imprensa" (Decreto $20.033,1931$, artigo $2^{\circ}$ ), instrumento que pode ser considerado o embrião do radiofônico Programa Nacional e da Agência Nacional. 
Ainda em 1931, o governo começa a regulamentar a radiodifusão no país, com o decreto $\mathrm{n}^{\circ}$ 20.047, determinando que a regulação é "da exclusiva competência da União". Em seu artigo 12, o decreto determina que "o serviço de radiodifusão é considerado de interesse nacional e de finalidade educacional". Verifica-se aqui, com essas duas iniciativas, a intenção dialética do governo em abarcar ambos processos sociais em curso. Por um lado, exercer algum controle sobre quem pode veicular conteúdos e, por outro, ter seu próprio instrumento de divulgação. Uma tendência onipresencial que estendeu-se aos dias atuais, através do controle de fluxos da liberação de verbas publicitárias.

O governo lança o Programa Nacional em 22 de julho de 1935, transformado em 1938 em A Hora do Brasil, com transmissão obrigatória em cadeia nacional de rádio e horário fixo das 19h às 20h. Em 1937 foi criada a Agência Nacional. Ambos integravam a estrutura oficial de informação, dentro do Departamento de Propaganda e Difusão Cultural (DPDC), órgão que sucedeu ao DOP, em 1934.

Segundo Aguiar e Lisboa (2016), o objetivo do governo com a Agência Nacional era o de alcançar jornais e emissoras em todo o país, como fornecedora de referência para os veículos da cobertura dos atos oficiais, além de produzir A Hora do Brasil.

Com a implantação do Estado Novo, o DPDC passa a Departamento Nacional de Propaganda (DNP) em 1938, e, em 1939, o órgão é reorganizado pelo decreto-lei 1.915, dando lugar ao Departamento de Imprensa e Propaganda (DIP). Segundo Jambeiro (2002), o DIP, criado para difundir a ideologia do regime e promover o presidente e as realizações do governo, exercia extremo controle e censura sobre a comunicação e a cultura.

O DIP tinha decisiva importância na missão de centralizar, orientar e coordenar a propaganda do Estado Novo, tanto no território nacional quanto no exterior. Para tal, elaborou e implementou uma propaganda ideológica sistemática, e criou mecanismos para bloquear a circulação de outras ideologias (JAMBEIRO, 2002, p.41).

Aguiar e Lisboa (2016) destacam que "a configuração getulista para a comunicação estatal subordinou a uma mesma estrutura burocrática tanto a censura quanto a distribuição de informações", já que o DIP era responsável pela Hora do Brasil e pela Agência Nacional.

Com o fim do Estado Novo, em 1945, o DIP é sucedido pelo Departamento Nacional de Informações (DNI), este sendo extinto em 1946. A Agência Nacional passa a ser subordinada ao Ministério da Justiça e Negócios Interiores.

\section{ERA DE OURO DO RÁDIO}

A década de 1940 viu o florescimento da Rádio Nacional do Rio de Janeiro. Em 1940, a emissora é incorporada à União por meio do decreto-lei $n^{\circ} 2.073$. Segundo Azevedo et al (2009 p.270), o ato foi fundamental na "estratégia de fortalecimento dos instrumentos de difusão ideológica vinculados ao projeto do Estado Novo". A emissora foi mantida como um veículo comercial na programação e no financiamento por anúncios publicitários, alcançando o primeiro lugar em audiência e faturamento (PINHEIRO, 2005, p.11). Aqui vemos a postura ativa presente na discussão da EPC, com a produção de conhecimento e análise da realidade controladas (VALENTE, 2009, p.9), no caso, pelo Estado em prol de seus interesses. 
Alguns marcos da Rádio Nacional desse período são o Radioteatro Colgate e o Repórter Esso, patrocinado por uma empresa petrolífera estrangeira. Em 1942 foram inauguradas três estações de ondas curtas direcionadas para os Estados Unidos, Europa, Ásia e parte da África. No início dos anos 1940, foi a principal emissora da América Latina e uma das cinco mais potentes do mundo (PINHEIRO, 2005, p.51). Lembrando Barbero, a música popular ganha imensa projeção articuladamente associada a ações do governo. Nessa mesma Rádio Nacional, pelo lado governamental, a redação de notícias foi mobilizada para a campanha do petróleo, que culminou na criação da Petrobras em 1954 (Idem, p.120).

Com a construção da nova capital do país, em 1958 foi criada a Rádio Nacional de Brasília. Na inauguração da emissora, o presidente Juscelino Kubitschek destacou a importância da rádio para manter o país informado sobre as obras no Planalto Central, utilizando, assim, a emissora como veículo de propaganda de seus feitos, ao mesmo tempo em que prestava um serviço público para os trabalhadores deslocados para o canteiro de obras e suas famílias.

\begin{abstract}
Das vertentes amazônicas às coxilhas gaúchas, e dos contra-fortes andinos ao litoral atlântico, Brasília fará ouvir a sua voz, a partir deste momento, graças aos possantes transmissores da Rádio Nacional, que ora inauguramos. Milhões de lares disseminados nos mais recônditos recessos do nosso território participarão, assim, de ora em diante, da presença física e da convivência de Brasília, e reconhecerão a fisionomia familiar desta nova metrópole (KUBITSCHEK, in Rádios EBC, 2019).
\end{abstract}

A partir de meados da década de 1950, acentuou-se a migração de patrocinadores e verbas publicitárias do rádio para a televisão (PINHEIRO, 2005, p.144), dentro do modelo industrial de comunicação de massa consolidado pelo rádio e adotado pela televisão no país (JAMBEIRO, 2002, p.49) e analisado pelos primeiros estudos da EPC (MOSCO, 2009, p.69).

\title{
TV EDUCATIVA
}

Como instrumento de educação, a década de 1960 teve muitos marcos na TV. Segundo Valente (2009), tal agenda política não foi gratuita.

(...) incentivada como um importante instrumento do Estado de resposta à demanda de massificação da educação frente às necessidades dos capitais nacionais e internacionais por mão-deobra mais qualificada, ou minimamente instruída, no bojo do processo de industrialização do país (VALENTE, 2009, p.55).

Dentro da instrumentalização do meio para uso segundo as diretrizes políticas do governo em consonância com o capital, em 1960, o decreto $n^{\circ} 49.259$ institui a Campanha Nacional de Radiodifusão Educativa (CNRE), com os objetivos de "promover a irradiação de programas científicos, literários e artísticos de caráter educativo" e "orientar a radiodifusão como meio auxiliar de educação e ensino" $\left(\operatorname{artigo} 2^{\circ}\right)$.

\footnotetext{
1 Disponível em: http://radios.EBC.com.br/especiais/2019/05/conheca-historia-da-radio-nacional-debrasilia-fundada-na-capital-em-1958 (acesso em 12/08/19).
} 
Em 1962 a lei $n^{\circ} 4.117$ institui o Código Brasileiro de Telecomunicações (CBT), regulamentado pelo decreto $n^{\circ} 52.795$, cujo artigo $3^{\circ}$ estabelece que

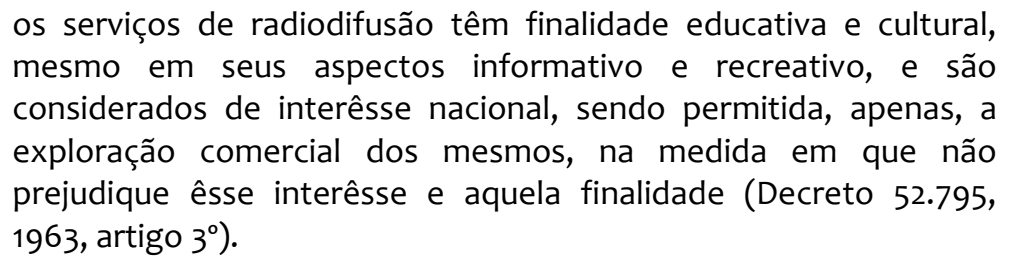
mesmo em seus aspectos informativo e recreativo, e são considerados de interêsse nacional, sendo permitida, apenas, a exploração comercial dos mesmos, na medida em que não prejudique êsse interêsse e aquela finalidade (Decreto 52.795, 1963 , artigo $3^{\circ}$ ).

Portanto, a finalidade educativa e cultural do rádio e da TV foi prevista em lei a ser acatada pelas emissoras comerciais. Em 1967, o decreto-lei $n^{\circ} 236$ modifica o CBT instituindo a televisão educativa de caráter não-comercial. Com isso, Azevedo et al. (2009, p.43) destacam que foi possível criar as emissoras estaduais e universitárias.

Na história da Rádio MEC, em 1967 é criada a Fundação Centro Brasileiro de TV Educativa (FCBTV/MEC), que passa a administrar a emissora e produz conteúdos educativos usados por diversas emissoras de TV do país, inclusive comerciais.

O governo federal passa de produtor para operador com a outorga do Canal 2 no Rio de Janeiro para a Fundação. A TVE entrou no ar de forma experimental no dia 5 de novembro de 1975 e definitiva no dia 4 de fevereiro de 1977. A controladora da Rádio Nacional inaugura a TV Nacional Brasília em 1960. Segundo Jambeiro (2002, p.62), a emissora "operava como estação retransmissora para redes não-comerciais e como geradora de discursos oficiais do presidente e de seus ministros", sendo usada para fins educativos e governamentais.

Em 1969, é inaugurada a TV Educativa do Maranhão, vinculada à Secretaria de Educação e Cultura, com finalidade de atender à demanda por educação no estado (PASSINHO, 2008, p.48).

\section{COMUNICAÇÃO DE GOVERNO}

Em 1963, no governo João Goulart, é criada a Secretaria de Imprensa, vinculada ao Gabinete Civil da Presidência da República, que tinha entre as funções "distribuir todo o noticiário referente às atividades da Presidência da República" (Decreto 51.872, 1963, artigo 19, alínea b). Em 1965 a Secretaria passa a "selecionar, para divulgação na Agência Nacional e órgãos congêneres, as informações e atos do Govêrno" (Decreto 56.596, 1965, artigo 32), aumentando a organização da comunicação de governo. Lembremos que as receitas publicitárias do Governo Federal tem um papel determinante na condução da comunicação pública e privada, porque o governo, "na condição de anunciante e respectivamente comprador da mercadoria audiência, contribui para manutenção do mercado oligopólico de comunicação, em detrimento do sistema público" (SANTOS, 2018).

Na Agência Nacional, em 1960 foi instalada a rede Telex no Brasil, criando a estrutura de distribuição de notícias das agências para as redações. Em 1961 o presidente Jânio Quadros conferiu ao órgão o poder de convocar cadeia de rádio e televisão, além de cuidar da execução técnica. Aguiar e Lisboa (2016) destacam que o órgão permaneceu orientado pela política e ideologia do governo da vez e passou a ser visto como "órgão de divulgação oficial” pela ditadura militar após o golpe de 1964.

A esta altura, a Rádio Nacional foi utilizada para cobrir a Amazônia com a ideologia do regime, substituindo o projeto de fazer transmissões internacionais, como outras emissoras públicas faziam (PIERANTI, 2018, p.129). 


\section{RADIOBRÁS E EBN}

Pieranti (2018, pp.126 e 127) destaca que em meados da década de 1970 havia dezenas de emissoras educativas vinculadas à União, aos estados, municípios ou universidades, mas sem coordenação entre elas. Em 15 de dezembro de 1975, a lei ${ }^{\circ}$ 6.301 cria a Empresa Brasileira de Radiodifusão (Radiobrás), incorporando a Rádio Nacional do Rio de Janeiro, Fundação Rádio Mauá e TV Rádio Nacional de Brasília, vinculada ao Ministério das Comunicações, com os seguintes objetivos:

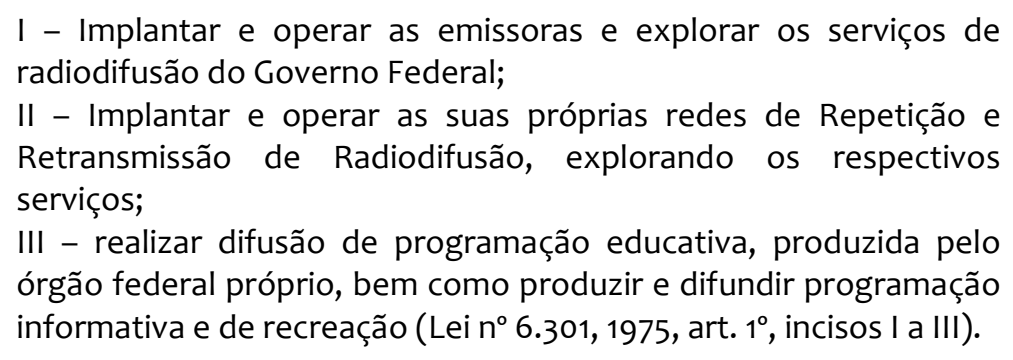

Para Valente (2009, p.64), o objetivo do governo foi ampliar o projeto de radiodifusão, incluindo a produção de informações e regiões sem cobertura comercial. Pieranti (2018, p.129) chamou a atenção para a importância dessa capilaridade radiofônica. "Na prática, a Radiobrás tornou-se um receptáculo de emissoras pequenas, deficitárias, sem grandes projetos de programação e muito menos importantes que a imponente, porém fragilizada, Rádio Nacional” (PIERANTI, 2018, p.129).

Em 1976, entra no ar a Rádio Nacional FM, a primeira emissora FM de Brasília, e em 1977 é inaugurada a Rádio Nacional da Amazônia, com a missão de integrar a Amazônia Legal ao restante do país, dentro do projeto dos governos militares. Com a profusão de $\mathrm{FMs}$ e a transferência das decisões para a Radiobrás, em Brasília, a Nacional do Rio de Janeiro, em AM, enfrenta dificuldades para renovar equipamentos e pessoal (PINHEIRO, 2005, p.155).

Em maio de 1979, a lei nº 6.650 cria a Secretaria de Comunicação Social da Presidência da República, à qual é vinculada a Radiobrás, e transforma a Agência Nacional em Empresa Brasileira de Notícias (EBN), também vinculada à Secom. Segundo Bucci (2008, p.87), a EBN produzia noticiários sobre o governo, com boletins diários, entrevistas e o programa $A$ Voz do Brasil.

No início dos anos 1980, Valente (2009, p.69) destaca que, com a desmobilização do projeto educativo militar e a abertura política após a ditadura, as TVs educativas se dedicam a conteúdos generalistas qualificados. Uma nova emissora é criada em 1983, a Rádio MEC FM do Rio de Janeiro, especializada em música de concerto e instrumental.

Em 1986, a TV Educativa do Maranhão é federalizada e passa a retransmitir a TVE do Rio de Janeiro. A decadência do sistema de comunicação federal segue com o decreto $n^{\circ}$ 95.955, de 1988, que autoriza a Radiobrás a alienar 14 emissoras de rádio e uma de televisão (PIERANTI, 2018, p.130), com o governo abrindo mão de operar uma rede nacional de emissoras.

\section{CONSTITUIÇÃO DE 1988}

Na década de 1980, o grande marco legal é a Constituição Federal de 1988, que prevê no artigo 223 a complementaridade dos sistemas públicos, estatal e privado de 
radiodifusão. Segundo Pieranti (2018, p.35), essa é a primeira referência ao termo comunicação pública em texto legal no país. Isso mostra que havia uma intercessão entre manifestação cultural, mesmo que intermediada pelos detentores dos veículos midiáticos, e a perspectiva do uso político das redes, não uma consciência politicamente estabelecida de uma comunicação pública institucionalizada.

Segundo Venício Lima (in RAMOS et al, 2017), a Constituição previu como um direito de toda brasileira e todo brasileiro ser bem informada e informado, para sair do círculo vicioso midiático diante da concentração de meios vigente no Brasil, e ter a capacidade de formular sua própria opinião crítica.

Ainda na década de 1980, diversos decretos alteram a estrutura de comunicação do governo federal e a vinculação da Radiobrás e da EBN, que passam pelo Ministério das Comunicações, Gabinete Civil da Presidência e Ministério da Justiça. Até o decreto $n^{\circ}$ 96.212, de 1988, incorporar a EBN à Radiobrás, que passa a se chamar Empresa Brasileira de Comunicação. Com isso, a Rádio Nacional passa a ser a geradora da Voz do Brasil e das Redes Obrigatórias de Rádio, incorporando as funções de comunicação governamental antes exercidas pela Agência Nacional e EBN.

A fusão descontinuou a prestação do serviço noticioso da EBN, mas em 1990, o governo Fernando Collor de Mello cria a Agência Brasil, dentro da Radiobrás, "para difundir notícias governamentais e abastecer os veículos de comunicação" (AGUIAR e LISBOA, 2016). Em 1997, é lançado o site da Agência Brasil e em 1998 a redação é remodelada e ampliada a produção de notícias. No ano 2000 a distribuição de notícias passou a ser feita apenas pela internet (Idem). Bucci (2008, p.137) descreve a Agência Brasil no fim da década de 1990 como um "escoadouro automático de informes governamentais", ou seja, um aparato da máquina político-administrativa.

No curso da Rádio MEC e da TVE, em 1990 a FCBTVE vira Fundação Roquette-Pinto, vinculada ao Ministério da Educação. De acordo com Valente (2009, p.78), essa mudança inicia a desestruturação dos aparatos estatais de comunicação. Em 1998, a fundação dá lugar à Associação de Comunicação Educativa Roquette-Pinto (Acerp). Para Leal Filho (in CARMONA, 2003, p.82), a medida retirou entraves burocráticos da TVE, mas não aumentou a autonomia da emissora.

Na virada do milênio, a Agência Brasil funcionava como uma típica agência de notícias oficial (AGUIAR e LISBOA, 2016). Na Rádio Nacional, em 2002, a precarização leva funcionários do Rio de Janeiro a se organizar contra a ameaça da emissora passar a ser retransmissora da Nacional de Brasília (PINHEIRO, 2005, p.155).

O jornalista Eugênio Bucci assume a presidência da Radiobrás em 2003, após a eleição de Luiz Inácio Lula da Silva, e dá novo direcionamento à empresa para ter "foco no cidadão" e ir contra a cultura de que uma estatal com emissoras existe para defender o governo e preservar a imagem dos governantes (BUCCl, 2008, p.22).

A Rádio Nacional do Rio de Janeiro é reequipada e reinaugurada em 2004, com a programação renovada. A Radioagência Nacional é lançada no mesmo ano, com a distribuição gratuita pela internet dos conteúdos jornalísticos produzidos pela Rádio Nacional. Em 2006, é inaugurada a Rádio Mesorregional do Alto Solimões, em parceria com o Ministério da Integração Nacional, cobrindo a tríplice fronteira entre Brasil, Colômbia e Peru, com informação, serviços e cultura nacional e regional.

Em 2006, o site da Agência Brasil adota o padrão Creative Commons 2.5 de licenciamento de conteúdo, que permite a reprodução gratuita desde que citada a fonte. Na televisão, Bucci (2008, p.124) destaca a ampliação da grade da TV Nacional 
e da NBR de 18 para 24 horas diárias, além da retransmissão de programas por outras emissoras, como Diálogo Brasil e Ver TV.

Todas essas mudanças condizem com o novo direcionamento do governo que tomou posse, voltando a produção da comunicação que estava ao seu alcance para alcançar uma maior parcela da população, numa tentativa de viabilização dos princípios de comunicação pública.

\section{EBC - UMA TENTATIVA DE CONSOLIDAÇÃO DA COMUNICAÇÃO PÚBLICA}

Com o novo governo, as discussões na sociedade civil sobre a comunicação pública aumentaram, com eventos como o encontro O Desafio da TV Pública, organizado pela TVE em 2003, e o I Fórum Nacional de TVs Públicas, em 2007, que resultou no manifesto Carta de Brasília. O documento defende uma rede com independência editorial de mercados e governos, que estimule a formação crítica do cidadão, valorize a produção independente, regionalizada e expresse a diversidade de gênero, étnico-racial, de orientação sexual, regional e social do Brasil, sintonizados com os princípios internacionais da comunicação pública.

Em 10 de outubro de 2007, é publicada a Medida Provisória 398, convertida na Lei ${ }^{\circ}$ 11.652/2008, que institui os princípios e objetivos dos serviços de radiodifusão pública explorados pelo Poder Executivo e cria a Empresa Brasil de Comunicação. A primeira diretora-presidente da EBC, a jornalista Tereza Cruvinel, lembra que o projeto de criar a empresa enfrentou "muita incompreensão e resistência", além de não ter tido força política para chegar a todo o país.

\footnotetext{
Hoje, vejo que a missão de criar a TV Pública não foi acompanhada de um passo importante, a garantia de canais para a nova emissora pelo menos em três capitais. A União, na verdade, só dispunha de três canais: um em Brasília, outro no Rio e um no Maranhão. Mas, aos trancos, contornamos este grande obstáculo (CRUVINEL in PAULINO e SILVA, 2013, p.28).
}

A EBC foi criada incorporando os bens, serviços e funcionários da Radiobrás e da Acerp. Segundo Azevedo et al (2009, p.45), "a visão por trás do modelo da EBC aproxima-se daquela que compreende a de mídia pública como um espaço democrático necessário entre o mercado e o Estado". No dia 2 de dezembro de 2007 a TV Brasil entra no ar no Rio de Janeiro, São Paulo, Brasília e São Luís, com 50 geradoras e mais de 700 retransmissoras pelo país. A transmissão é obrigatória nos pacotes básicos de TVs por assinatura e disponível via antena parabólica.

A autonomia da EBC em relação ao governo federal seria garantida pelo mandato de quatro anos do diretor-presidente não coincidente com o do mandatário do país; pela Ouvidoria, encarregada de exercer a crítica interna da programação; e pelo Conselho Curador, formado por 22 membros, 15 deles da sociedade civil. As funções do Conselho", eram "zelar pelos princípios e pela autonomia da EBC, impedindo que houvesse ingerência indevida do Governo e do mercado sobre a programação e gestão"; e "representar os anseios da sociedade, em sua diversidade, na aprovação das diretrizes de conteúdo e do plano de trabalho".

\footnotetext{
${ }^{2}$ Disponível em http://www.EBC.com.br/institucional/conselho-curador (acesso em 02/12/19)
} 
Para garantir alguma autonomia financeira, foi criada a Contribuição para o Fomento da Radiodifusão Pública, com recursos do Fundo de Fiscalização das Telecomunicações, pago pelas empresas. Porém, disputas judiciais e cortes impedem os recursos de chegarem à EBC. Na prática, a autonomia da empresa sempre foi prejudicada por ela depender do Erário, ser vinculada a órgãos da Presidência da República e ter a maioria do Conselho de Administração formada por membros do governo.

Apesar dessas dificuldades, princípios de comunicação pública estiveram presentes nos primeiros anos da EBC. A principal face da mudança foi a TV Brasil, uma das únicas TVs abertas com conteúdo infantil; uma das que mais exibem cinema nacional; veiculou novela e desenho animado só com personagens negros; oferta jornal em libras, música clássica, debate sobre a mídia e artes da periferia. Teve bons índices de audiência com a Série $C$ do Campeonato Brasileiro de Futebol e o Desfile das Campeãs do Carnaval carioca. Exemplos de programas que preconizam os princípios de diversidade de oferta, pluralidade de fontes, fomento ao pensamento crítico e complementariedade de conteúdos não ofertados por canais comerciais, caros à comunicação pública.

O primeiro ouvidor-geral da EBC, Laurindo Leal Filho (in PAULINO e SILVA, 2013, p.46), afirma que a implantação da empresa foi "um salto histórico" para a comunicação brasileira. Como dificuldades, Tereza Cruvinel (in RAMOS et al, 2017) destaca a concorrência consolidada e oposição ferrenha dos canais comerciais, bem como as restrições orçamentárias do setor público. Como coloca Mosco (2009, p.98), tal oposição coaduna com a visão das elites nacionais, detentoras dos meios de comunicação e alinhadas às ferramentas comunicacionais de informação e entretenimento que os Estados Unidos começaram a implantaram ainda durante a Segunda Guerra Mundial.

Em outubro de 2011 foi lançado o Portal EBC ${ }^{3}$, que integra os conteúdos dos veículos da emrpesa. Em 2013, foram lançadas as páginas da Agência Brasil em inglês e em espanhol e, no início de 2016, a ABr enviou correspondentes ao Rio Grande do Sul, Minas Gerais, Bahia e Pernambuco, além de Ceará e Amazonas, regionalizando a cobertura jornalística, outra característica da comunicação pública.

Também em 2011, a EBC realizou, em parceria com a Unesco, o Seminário Internacional de Mídias Públicas. Os debates de alto nível, com participação de organizações como National Public Radio, Unesco Brasil, New York University, Télam e BBC Trust, contribuíram para a elaboração do Manual de Jornalismo da EBC.

Ainda em vigor, o manual tem o lema "Somente a verdade" (BEIRÃO, 2012) e orienta priorizar os direitos humanos e minorias, mostrando histórias e dando voz a quem não tem espaço na mídia comercial. São vedadas a objetificação da mulher, a exploração da desgraça alheia e o sensacionalismo. A norma traz anexos a Declaração Universal dos Direitos Humanos, o Código de Ética dos Jornalistas Brasileiros, a Convenção Interamericana para Prevenir, Punir e Erradicar a Violência contra a Mulher e a Declaração da Unesco sobre as mídias.

\footnotetext{
${ }^{3}$ Disponível em http://www.EBC.com.br/institucional/veiculos/portal-EBC (acesso em 24/08/19)
} 


\section{CRISE POLÍTICA E MP 744}

Em meio à crise política que levou ao impedimento da presidenta Dilma Rousseff, a EBC passou por tentativas de consolidação da comunicação pública e também de uso político. Em agosto de 2015, o Conselho Curador reuniu no Seminário Modelo Institucional da EBC especialistas e a sociedade civil para discutir os rumos da empresa, no qual foram apresentadas propostas para aumentar a autonomia frente ao governo.

As disputas políticas se intensificaram em 2016 e após a votação do impeachment no Senado, em 12 de maio, que abriu o processo e afastou Dilma temporariamente, o presidente interino Michel Temer exonerou o diretor-presidente da EBC, Ricardo Melo, e nomeou Laerte Rímoli. A lei 11.652 garantia o mandato ao diretor presidente da EBC e Melo conseguiu uma liminar no Supremo Tribunal Federal, retomando as funções no dia 3 de junho, com Rímoli também no cargo, mas sem exercê-lo.

Com o impedimento definitivo de Dilma, aprovado em 31 de agosto, no dia $1^{\circ}$ de setembro é editada a Medida Provisória 744, que desfigura o caráter público da EBC ao retirar o mandato do diretor-presidente, extinguir o Conselho Curador e vincular a empresa à Casa Civil. Com isso, o ministro do STF Dias Tóffoli suspende a liminar concedida a Melo, por perda de objeto, e Rímoli reassume a presidência da EBC.

Dezenas de pessoas que ocupavam funções comissionadas foram demitidas e vários programas foram retirados do ar sem aviso aos espectadores e ouvintes, numa clara disputa de poder e narrativas dentro da empresa, com o governo demonstrando a força que tem para transformar, de uma hora para outra, toda a linha editorial e de programação das emissoras que deveriam ser públicas.

A MP 744 foi convertida na lei $n^{\circ} 13.417 / 2017$, incluindo um Comitê Editorial consultivo para substituir o Conselho Curador, mas com funções figurativas. Até maio de 20200 Comitê não havia sido implantado e o projeto de correspondentes nacionais da Agência Brasil foi encerrado em agosto de 2017.

Com o governo Jair Bolsonaro, no dia 9 de abril de 2019 a portaria EBC 216 unificou as grades da TV Brasil com a TV NBR. Em meados de 2020, permanecem as incertezas sobre o futuro da EBC e da comunicação pública no país, com a empresa incluída no Programa de Parcerias de Investimentos (PPI) e diversas denúncias de censura e interferência nos programas das emissoras e agências da EBC.

\section{CONCLUSÃO}

Ao percorrer a história dos veículos e agências que hoje compõem a EBC, verifica-se uma miscelânea de conceitos e projetos que guiaram a comunicação de serviço público nesse quase um século de radiodifusão no país. As bases políticas para a instalação de um modelo funcional de comunicação pública apontam para si próprias. Com um modelo comercial implantado desde o início, apesar da proposta educativa da primeira emissora, falta no Brasil, até hoje, um entendimento da comunicação pública. A falta de projeto para o setor é verificada nas constantes mudanças na legislação e órgãos de controle de informação no decorrer dos tempos.

Faltou também à EBC aprovação social, já que "nenhum sistema público se consolidou de fato sem sustentar um bom nível de legitimação perante a sociedade civil" (AZEVEDO et al, 2009, p.308) e todos os governos fazem uso do aparato disponível. Apesar da ameaça de privatização ou extinção da EBC, a apropriação de uma rede capilar no território brasileiro reflete-se em modificações feitas pelo 
governo atual para atender demandas próprias. Os princípios de comunicação pública previstos em lei, na Constituição Federal e mesmo a pequena participação social do Comitê Editorial, a cada dia se consolidam mais como letra morta no papel.

Fica evidente também, no processo de pesquisa, a quase ausência de estudos em aspectos pontuais para a análise das ferramentas de controle do poder governamental junto às empresas de comunicação, como a distribuição da verba publicitária do Governo Federal. Um exemplo da necessidade de aprofundamento da reflexão a respeito dos modos possíveis de autonomia da gestão dos veículos a serviço da comunicação pública.

As modificações sazonais, no entanto, e não a total extinção da EBC, demonstram a necessidade de existência da comunicação pública. Uma estrutura de expressão voltada para as necessidades de educação, autoconhecimento e desenvolvimento sociocultural, notadamente em um país de dimensões continentais como o Brasil.

Artigo recebido em 01/02/2020 e aprovado em 23/04/2020.

\section{BIBLIOGRAFIA}

AGUIAR, Pedro; LISBOA; Juliana. Da Agência Nacional à Agência Brasil. $6^{\circ}$ Encontro Regional Sul de História da Mídia. Alcar Sul: junho 2016.

AZEVEDO, Flávia; RODRIGUES, Diogo Moyses; SILVA, Sivaldo Pereira; VALENTE, Jonas. Sistemas públicos de comunicação no mundo. São Paulo: Paulus, Intervozes, 2009. (Coleção Comunicação).

BEIRÃO, Nereide (Presidente da Comissão); ACHILIS, Antonio (Redação). Manual de Jornalismo da EBC. Brasília: 11 de junho de 2012.

BRASIL. Decreto $\mathbf{n}^{\circ}$ 20.033, de 25 de maio de 1931. Cria o Departamento Oficial de Publicidade. Rio de Janeiro: Governo Provisório da República dos Estados Unidos do Brasil, 1931.

BRASIL. Decreto $\mathbf{n}^{\circ} \mathbf{2 0 . 0 4 7}$, de 27 de maio de 1931. Regula a execução dos serviços de radiocomunicações no território nacional. Rio de Janeiro: Governo Provisório da República dos Estados Unidos do Brasil, 1931.

BRASIL. Decreto-Lei $n^{\circ}$ 1.915, de 27 de dezembro de 1939. Cria o Departamento de Imprensa e Propaganda e dá outras providências. Rio de Janeiro: Presidência da República, 1939.

BRASIL. Decreto-Lei $\mathbf{n}^{\circ} \mathbf{2 . 0 7 3}$, de 8 de março de 1940. Incorpora ao patrimônio da União a Estrada de Ferro São Paulo-Rio Grande e as empresas a ela filiadas. Rio de Janeiro: Presidência da República, 1940.

BRASIL. Decreto $n^{\circ}$ 49.259, de 17 de novembro de 1960. Institui a Campanha de Radiodifusão Educativa. Brasília: Presidência da República, 1960.

BRASIL. Lei $n^{\circ}$ 4.117, de 27 de agosto de 1962. Institui o Código Brasileiro de Telecomunicações. Brasília: Presidência da República, 1962.

BRASIL. Decreto $n^{\circ}$ 52.795, de 31 de outubro de 1963. Aprova o Regulamento dos Serviços de Radiodifusão. Brasília: Presidência da República, 1963.

BRASIL. Decreto $\mathrm{n}^{\circ} \mathbf{5 1 . 8 7 2}$, de $\mathbf{1}^{\circ}$ de abril de 1963 . Estabelece novo regimento para o Gabinete Civil da Presidência da República. Brasília: Presidência da República, 1963. 
BRASIL. Decreto $n^{\circ}$ 56.596, de 21 de julho de 1965. Estabelece nôvo regimento para o Gabinete Civil da Presidência da República. Brasília: Presidência da República, 1965.

BRASIL. Decreto-Lei $\mathbf{n}^{\circ} \mathbf{2 3 6}$, de 28 de fevereiro de 1967. Complementa e modifica a Lei número 4.117 de 27 de agôsto de 1962. Brasília: Presidência da República, 1967.

BRASIL. Lei $n^{\circ}$ 6.301, de 15 de dezembro de 1975. Institui política de exploração de serviço de radiodifusão de emissoras oficiais, autoriza o Poder Executivo a constituir a Empresa Brasileira de Radiodifusão. Brasília: Presidência da República, 1975.

BRASIL. Lei $n^{\circ}$ 6.650, de 23 de maio de 1979. Dispõe sobre a criação, na Presidência da República, da Secretaria de Comunicação Social, altera dispositivos do Decreto-Lei $n^{\circ}$ 200, de 25 de fevereiro de 1967, e dá outras providências. Brasília: Presidência da República, 1979.

BRASIL. Decreto $\mathbf{n}^{\circ} \mathbf{9 5 . 9 5 5}$, de 22 de abril de 1988. Dá nova redação ao art. $1^{\circ}$ do Decreto $n^{\circ}$ 95.916, de 12 de abril de 1988, que autoriza RADIOBRÁS a alienar as emissoras de rádio e televisão que menciona. Brasília: Presidência da República, 1988.

BRASIL. Decreto $\mathbf{n}^{\circ} \mathbf{9 6 . 2 1 2}$, de 22 de junho de 1988. Dispõe sobre a incorporação da Empresa Brasileira de Noticias à Empresa Brasileira de Radiodifusão e dá outras providências. Brasília: Presidência da República, 1988.

BRASIL. Constituição da República Federativa do Brasil de 1988. Brasília: Assembleia Nacional Constituinte, 1988.

BRASIL. Medida provisória $\mathbf{n}^{\circ}$ 398, de 10 de outubro de 2007. Institui os princípios e objetivos dos serviços de radiodifusão pública explorados pelo Poder Executivo ou outorgados a entidades de sua administração indireta, autoriza o Poder Executivo a constituir a Empresa Brasil de Comunicação - EBC, e dá outras providências. Brasília: Presidência da República, 2007.

BRASIL. Lei ${ }^{\circ}$ 11.652, de 7 de abril de 2008. Conversão da MP 398; altera a Lei no 5.070, de 7 de julho de 1966. Brasília: Presidência da República, 2008.

BRASIL. Medida provisória $\mathrm{n}^{\circ} \mathbf{7 4 4}$, de $\mathbf{1}^{\circ}$ de setembro de 2016 . Altera a Lei $n^{\circ} 11.652$. Brasília: Presidência da República, 2016.

BRASIL. Lei $n^{\circ} \mathbf{1 3 . 4 1 7}$, de $1^{\circ}$ de março de 2017. Altera a Lei $n^{\circ} 11.652$, de 7 de abril de 2008. Brasília: Presidência da República, 2017.

BUCCl, Eugênio. Em Brasília, 19 horas. Rio de Janeiro: Editora Record, 2008.

BUCCI, Eugênio; CHIARETTI, Marco; FIORINI, Ana Maria. Indicadores de Qualidade nas Emissoras Públicas. Série Debates $\mathrm{Cl} n^{\circ} 10$. Brasil: Representação da Unesco, junho de 2012. Acesso em: 27 dez. 2019.

CARMONA, Beth (Organização). O desafio da TV Pública. Rio de Janeiro: TVE Rede Brasil, 2003.

CARTA DE BRASÍLIA. Manifesto pela TV Pública independente e democrática. I Fórum Nacional de TVs Públicas. Brasília: 11 mai. 2007.

EBC. Portaria-Presidente $\mathbf{n}^{\circ} \mathbf{2 1 6}$, de 09 de abril de 2019. Dispõe sobre a programação televisiva da EBC. Brasília: Diretoria-executiva, 2019.

JAMBEIRO, Othon. A TV no Brasil do século XX. Salvador: EDUFBA, 2002.

MARTÍN-BARBERO, Jesús. Ofício de cartógrafo. $1^{\text {a }}$ edición. Santiago: Fondo de Cultura Económica, 2002.

MENDEL, Toby. Serviço público de radiodifusão. Brasília: UNESCO, 2011. 
MOSCO, Vincent. The Political Economy of Communication. 2nd Edition. London: Sage, 2009. E-book.

PASSINHO, Sandra Regina de Oliveira Marques. Educação “Fora do Ar". 2008. 198 f. Dissertação (Mestrado) - Universidade Estácio de Sá, Mestrado em Educação, Rio de Janeiro, 2008.

PAULINO, Fernando Oliveira; SILVA, Luiz Martins da (Organizadores). Comunicação pública em debate: ouvidoria e rádio. Brasília: Editora Universidade de Brasília, 2013.

PIERANTI, Octavio Penna. A radiodifusão pública resiste. Brasília: FAC Livros, 2018.

PINHEIRO, Claudia (org). A Rádio Nacional: alguns momentos que contribuíram para o sucesso da Rádio Nacional. Rio de Janeiro: Nova Fronteira, 2005.

RAMOS, Murilo Cesar et al (organizadores). Em defesa da comunicação pública. Brasília: FAC Livros, 2017. E-book.

SANTOS, Pedro Alexandre Oliveira. A Política de Distribuição da Verba Publicitária do Governo Federal no Brasil (2000/2014). Dissertação (Mestrado) - Universidade Federal de Sergipe Programa de Pós-Graduação em Comunicação, São Cristóvão, 2018.

VALENTE, Jonas. A TV Pública no Brasil. 2009. 208 f. Dissertação (Mestrado) Universidade de Brasília, Programa de Pós-Graduação em Comunicação, Brasília, 2009. 


\section{APÊNDICE - LINHA DO TEMPO DOS VEÍCULOS E AGÊNCIAS DE NOTÍCIAS DA EBC}

Legenda de cores:

\section{Marcos Legais}

Rádios MEC

Rádios Nacional

Agência Brasil

TV Brasil

\begin{tabular}{|c|c|c|c|c|}
\hline $\begin{array}{l}1923 \\
\text { Roquette-Pinto e } \\
\text { Morize criama } \\
\text { Rádio Sociedade }\end{array}$ & $\begin{array}{c}1931 \\
\text { Criaçãodo DOP } \\
\text { Regulaçãoda } \\
\text { radiocomunicação }\end{array}$ & $\begin{array}{c}1935 \\
\text { Estreia do } \\
\text { Programa Nacional }\end{array}$ & $\begin{array}{c}1936 \\
\text { Roquette-Pinto doa } \\
\text { a RádioSociedade } \\
\text { ao MEC }\end{array}$ & $\begin{array}{c}1936 \\
\text { Inauguração da } \\
\text { Rádio Nacional do } \\
\text { Rio de Janeiro }\end{array}$ \\
\hline \multicolumn{5}{|l|}{ V } \\
\hline $\begin{array}{c}1937 \\
\text { Criação da Agência } \\
\text { Nacional }\end{array}$ & $\begin{array}{l}1938 \\
\text { Estreia A Hora do } \\
\text { Brasil, em cadeia } \\
\text { nacional de rádio }\end{array}$ & $\begin{array}{c}1939 \\
\text { Criação do Dep. de } \\
\text { Imprensa e } \\
\text { Propaganda (DIP) }\end{array}$ & $\begin{array}{c}1940 \\
\text { Incorporação da } \\
\text { Rádio Nacional ao } \\
\text { Patrimônio da } \\
\text { União }\end{array}$ & $\begin{array}{c}1942 \\
\text { Inauguração de } \\
\text { três estações de } \\
\text { ondas curtas para o } \\
\text { exterior }\end{array}$ \\
\hline \multicolumn{5}{|l|}{ V } \\
\hline $\begin{array}{l}\text { Extinção do DIP, } \\
\text { Agência Nacional } \\
\text { vai para Minsitério } \\
\text { da Justiça }\end{array}$ & $\begin{array}{c}1958 \\
\text { Criação da Rádio } \\
\text { Nacionalde Brasilia }\end{array}$ & $\begin{array}{l}\text { Campanha } \\
\text { Nacionalde } \\
\text { Radiodifusão } \\
\text { Educativa }\end{array}$ & $\begin{array}{c}1960 \\
\text { Inauguração daTV } \\
\text { NacionalBrasília }\end{array}$ & $\begin{array}{l}1962 \\
\text { Código Brasileiro de } \\
\text { Telecomunicações }\end{array}$ \\
\hline \multicolumn{5}{|l|}{ 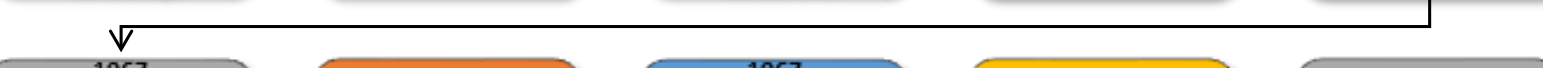 } \\
\hline $\begin{array}{c}1967 \\
\text { Modificação do } \\
\text { CBT cria televisão } \\
\text { educativa não- } \\
\text { comercial }\end{array}$ & $\begin{array}{l}1967 \\
\text { Criaçãoda Fund. } \\
\text { Centro Brasilero } \\
\text { de TV Educativa }\end{array}$ & $\begin{array}{c}1967 \\
\text { Agência Nacional } \\
\text { integrada ao Gab. } \\
\text { Civil da Pres. da } \\
\text { República } \\
\end{array}$ & $\begin{array}{c}1969 \\
\text { Inauguração da TV } \\
\text { Educativa do } \\
\text { Maranhão }\end{array}$ & $\begin{array}{l}1975 \\
\text { Lei } 6.301 \text { cria a } \\
\text { Radiobrás }\end{array}$ \\
\hline \\
\hline $\begin{array}{c}1975 \\
\text { Entra no ar a TVE } \\
\text { RJ }\end{array}$ & $\begin{array}{c}1976 \\
\text { Entra no ar a Rádio } \\
\text { NacionalFM de } \\
\text { Brasilia }\end{array}$ & $\begin{array}{c}1977 \\
\text { Inauguração da } \\
\text { Rádio Nacional da } \\
\text { Amazônia em OC }\end{array}$ & $\begin{array}{c}1979 \\
\text { Criação daSecome } \\
\text { vinculação da } \\
\text { Radiobrás }\end{array}$ & $\begin{array}{c}1979 \\
\text { Ag. Nacional vira } \\
\text { Empresa Brasilera } \\
\text { de Noticias (EBN), } \\
\text { vinculada à Secom }\end{array}$ \\
\hline \\
\hline $\begin{array}{c}1983 \\
\text { Criação da Rádio } \\
\text { MEC FM, com foco } \\
\text { na música clássica }\end{array}$ & $\begin{array}{l}1986 \\
\text { Federalização da } \\
\text { TV Educativa do } \\
\text { Maranhão }\end{array}$ & $\begin{array}{c}1988 \\
\text { EBN é extinta eo } \\
\text { serviçopassapara } \\
\text { a Radiobrás }\end{array}$ & $\begin{array}{c}1988 \\
\text { Decreto autoriza a } \\
\text { Radiobrás a alienar } \\
\text { emissoras de rádio } \\
\text { e televisão }\end{array}$ & $\begin{array}{c}1988 \\
\text { Constituição } \\
\text { Federalinstitui } \\
\text { complementari- } \\
\text { dadedossistemas }\end{array}$ \\
\hline \multicolumn{5}{|l|}{ V } \\
\hline $\begin{array}{c}\text { Rádio Nacional } \\
\text { passa a gerar a Voz } \\
\text { do Brasile as Redes } \\
\text { Obrigatórias }\end{array}$ & $\begin{array}{c}1990 \\
\text { FCBTV vira } \\
\text { Fundação } \\
\text { Roquette-Pinto }\end{array}$ & $\begin{array}{c}1990 \\
\text { Criação daAgência } \\
\text { Brasil na Radiobrás }\end{array}$ & $\begin{array}{c}1997 \\
\text { Lançamento dosite } \\
\text { da Agência Brasil }\end{array}$ & $\begin{array}{c}1998 \\
\text { Criação daTV NBR, } \\
\text { a TV do governo } \\
\text { federal }\end{array}$ \\
\hline \multicolumn{5}{|l|}{$V$} \\
\hline $\begin{array}{c}2003 \\
\begin{array}{c}\text { Eugênio Bucci dá } \\
\text { novo }\end{array} \\
\text { direcionamento à } \\
\text { Radiobrás }\end{array}$ & $\begin{array}{c}2004 \\
\text { Lançamanto da } \\
\text { Radioagência } \\
\text { Nacional }\end{array}$ & $\begin{array}{l}2006 \\
\text { Entra no ar a Rádio } \\
\text { Mesorregional do } \\
\text { Alto Solimões }\end{array}$ & $\begin{array}{l}2007 \\
\text { I Fórum Nacional } \\
\text { de TVs Públicas }\end{array}$ & $\begin{array}{c}2007 \\
\text { MP } 398 \text { cria a EBC, } \\
\text { convertida na Lei } \\
11.652 / 2008\end{array}$ \\
\hline \multicolumn{5}{|l|}{$V$} \\
\hline $\begin{array}{c}2007 \\
\text { Lançamento daTV } \\
\text { Brasil }\end{array}$ & $\begin{array}{l}2011 \\
\text { Lançamento do } \\
\text { Portal EBC }\end{array}$ & $\begin{array}{c}2014 \\
\text { Acerp volta a ser } \\
\text { vinculada ao MEC, } \\
\text { sem vínculo com } \\
\text { Rádio MEC } \\
\end{array}$ & $\begin{array}{c}2016 \\
\text { MP } 744 \text { retira } \\
\text { dispositivos de } \\
\text { comunicação } \\
\text { pública daEBC }\end{array}$ & $\begin{array}{c}2019 \\
\text { Portaria } 216 \mathrm{da} \\
\text { EBC unifica TV } \\
\text { Brasil coma TV } \\
\text { NBR }\end{array}$ \\
\hline
\end{tabular}

